\title{
Amino Acid Loss during Continuous Venovenous Hemofiltration in Critically III Patients
}

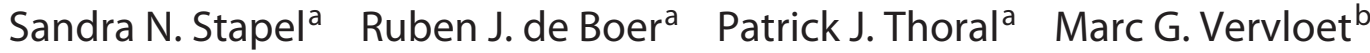 \\ Armand R.J. Girbes $^{\text {a }}$ Heleen M. Oudemans-van Straaten ${ }^{\text {a }}$ \\ ${ }^{a}$ Department of Adult Intensive Care Medicine, Amsterdam University Medical Centers, Vrije Universiteit, \\ Amsterdam, The Netherlands; ${ }^{b}$ Department of Nephrology, Amsterdam University Medical Centers, Vrije \\ Universiteit, Amsterdam, The Netherlands
}

\section{Keywords}

Adsorption · Amino acids · Continuous venovenous

hemofiltration $\cdot$ Critical care $\cdot$ Solute clearance

\section{Abstract}

Background/Objectives: During continuous venovenous hemofiltration (CVVH), there is unwanted loss of amino acids (AA) in the ultrafiltrate (UF). Solutes may also be removed by adsorption to the filter membrane. The aim was to quantify the total loss of AA via the CVVH circuit using a high-flux polysulfone membrane and to differentiate between the loss by ultrafiltration and adsorption. Methods: Prospective observational study in ten critically ill patients, receiving predilution $\mathrm{CVVH}$ with a new filter, blood flow $180 \mathrm{~mL} / \mathrm{min}$, and predilution flow 2,400 mL/h. Arterial blood, postfilter blood, and UF samples were taken at baseline, and 1, 8, and 24-h after CVVH initiation, to determine $\mathrm{AA}$ concentrations and hematocrit. Mass transfer calculations were used to determine AA loss in the filter and by UF, and the difference between these 2. Results: The median AA loss in the filter was $10.4 \mathrm{~g} /$ day, the median AA loss by UF was $13.4 \mathrm{~g} /$ day, and the median difference was -2.9

\begin{tabular}{ll}
\hline KARGER & $\begin{array}{l}\text { (c) } 2019 \text { The Author(s) } \\
\text { Published by S. Karger AG, Basel }\end{array}$ \\
E-Mail karger@karger.com & $\begin{array}{l}\text { This article is licensed under the Creative Commons Attribution- } \\
\text { NonCommercial-NoDerivatives 4.0 International License (CC BY- } \\
\text { NC-ND) (http://www.karger.com/Services/OpenAccessLicense). } \\
\text { Usage and distribution for commercial purposes as well as any dis- } \\
\text { tribution of modified material requires written permission. }\end{array}$
\end{tabular}

g/day (IQR -5.9 to $-1.4 \mathrm{~g} /$ day). For the individual $A A$, the difference ranged from $-1 \mathrm{~g} /$ day to $+0.4 \mathrm{~g} /$ day, suggesting that some AA were consumed or adsorbed and others were generated. AA losses did not significantly change over the 24-h study period. Conclusion: During CVVH with a modern polysulfone membrane, the estimated AA loss was 13.4 $\mathrm{g} /$ day, which corresponds to a loss of about $11.2 \mathrm{~g}$ of protein per day. Adsorption did not play a major role. However, individual AA behaved differently, suggesting complex interactions and processes at the filter membrane or peripheral AA production.

(c) 2019 The Author(s)

Published by S. Karger AG, Basel

\section{Introduction}

Acute kidney injury is a frequent manifestation of critical illness. Continuous venovenous hemofiltration $(\mathrm{CVVH})$ is commonly used as renal replacement therapy (RRT) modality. During CVVH, clearance is mainly achieved by convection, the process where solutes small enough to pass the pores in the semipermeable hemofilter are transported with plasma water to form the ultrafil- 
trate (UF). Due to the nonselectivity of the filtering process, "useful" solutes are also lost, including amino acids (AA). Studies investigating AA loss during RRT reported losses of 5-15 g/day, the degree depending on RRT modality, type of filter, and effluent rate [1-10]. These studies measured AA concentrations in the UF, and thereby only reported convective loss. Solutes can, however, also be removed by adsorption to the filter membrane. The degree of convective and adsorptive clearance depends on physical and chemical properties of solute and membrane. In vitro studies have shown that there can be considerable adsorptive losses of proteins, cytokines, and antibiotics under filtration conditions [11-17]. However, to our knowledge, no study reported absorptive AA loss during CVVH in vivo. In addition, other processes may contribute to the total flux of AA in the extracorporeal circuit. Therefore, the actual AA loss could be different from previously reported UF losses alone. This may have implications for protein requirements in patients receiving CVVH.

The primary aim of this study in critically ill patients was to quantify the total loss of AA in the extracorporeal CVVH circuit using a high-flux polysulfone membrane and to differentiate between the loss by ultrafiltration and adsorption. The secondary aim was to determine the loss of individual AA and their sieving coefficients (SC).

\section{Material and Methods}

This prospective observational study was performed at the mixed medical-surgical intensive care unit of the Amsterdam UMC, location VU University Medical Centre, The Netherlands. Adult critically ill patients, ready to receive CVVH with a new filter, were eligible for inclusion, provided the researcher was present to handle the samples (convenience sample). The Medical Ethics Committee of the VU University Medical Center waived the need for informed consent because no extra burden or risk was associated and patient data were coded (METC number 2013/308).

Continuous Venovenous Hemofiltration

Vascular access was obtained by an $11 \mathrm{~F}$ or $13 \mathrm{~F}$ double lumen catheter in the femoral or jugular vein (D-LINE ${ }^{\circledR}$ EXTRA-FLOW CATHETER, Joline). CVVH was performed using the multiFiltrate ${ }^{\circledR}$ device (Fresenius, Bad Homburg, Germany) with 2 filter types: Ultraflux AV 600S $1.4 \mathrm{~m}^{2}$ and Ultraflux AV $1000 \mathrm{~S} 1.8 \mathrm{~m}^{2}$ (Fresenius, Bad Homburg, Germany) having a similar polysulfone membrane with a wall thickness of $35 \mu \mathrm{m}$; only the surface area differed. The machine was set according to department protocol: blood flow $180 \mathrm{~mL} / \mathrm{min}$ and predilution replacement flow 2,400 $\mathrm{mL} / \mathrm{h}$. Net UF was adjusted to the desired fluid balance. Anticoagulation was primarily achieved with citrate as part of the predilution fluid or with heparin if systemic anticoagulation was required [18].

\section{Study Protocol}

The total study period was $24 \mathrm{~h}$. An arterial blood sample was taken before initiation of CVVH or before a new CVVH session to determine baseline plasma AA concentrations. Arterial blood was subsequently taken at 8 and $24 \mathrm{~h}$ after start and postfilter blood, and UF samples were taken 1,8 , and $24 \mathrm{~h}$ after initiation of CVVH to determine AA concentrations and hematocrit (Fig. 1). Arterial concentrations were used as prefilter AA concentrations. The baseline arterial sample was used as prefilter concentration at $1 \mathrm{~h}$, supposing that plasma concentrations of AA would not change within $1 \mathrm{~h}$.

Blood and UF for AA determination were collected in heparin tubes and directly centrifuged; $500 \mu \mathrm{L}$ plasma and UF were deproteinized using sulfosalicylic acid and immediately stored at $-80^{\circ} \mathrm{C}$ until assayed. Individual AA concentrations were determined using high-performance liquid chromatography [19]. The coefficient of variation for the AA measurements was $2.6 \pm 1.2 \%$.

\section{Other Measurements}

Demographic and clinical data, including age, gender, admission diagnosis, Acute Physiology and Chronic Health Evaluation II and III scores, CVVH characteristics, the type and amount of nutrition, and survival, were extracted from the patient data management system MetaVision ${ }^{\circledR}$ (iMDsoft, Tel Aviv, Israel).

The mass transfer and SC calculations are shown in Table 1.

AA concentrations were converted from $\mu \mathrm{mol} / \mathrm{h}$ to $\mathrm{mg} / \mathrm{h}$ by factoring the molecular weights of the individual AA. To estimate the median AA loss in g/day, the median of all obtained values of AA loss in $\mathrm{g} / \mathrm{h}$ was factored by 24 . To determine the SC for the individual AA, the mean SC of the 3 time points was calculated.

\section{Statistical Analysis}

Variables were tested for normal distribution using the Shapiro-Wilk test. Variables are presented as median (25th - 75th percentile) or mean (SD) where appropriate. To determine if AA loss varied in time, an analysis of variance was performed. SPSS IBM 22 (SPSS Inc., Chicago, IL, USA) and Graphpad prism 7.0 (GraphPad Software, La Jolla, CA, USA) were used. A $p<0.05$ was considered statistically significant.

\section{Results}

Ten patients were included. Baseline and clinical characteristics are shown in Table 2 . All patients were anuric (median urine production $9 \mathrm{~mL} / 24 \mathrm{~h}$, range $0-102 \mathrm{~mL} / 24$ h). Five patients were included when CVVH treatment was initiated and 5 after filter change. The femoral route was used in 6 and the jugular in 4 patients.

Baseline total AA plasma concentration per patient is shown in online supplemental Figure 1 (for all onlinesuppl. material, see www.karger.com/doi/10.1159/000500998). Patient 8 had acute ischemic liver failure and had the highest plasma AA concentration. The median baseline plasma concentration of the individual AA and the proportion of patients outside the reference range are presented in online supplementary Table 1. 


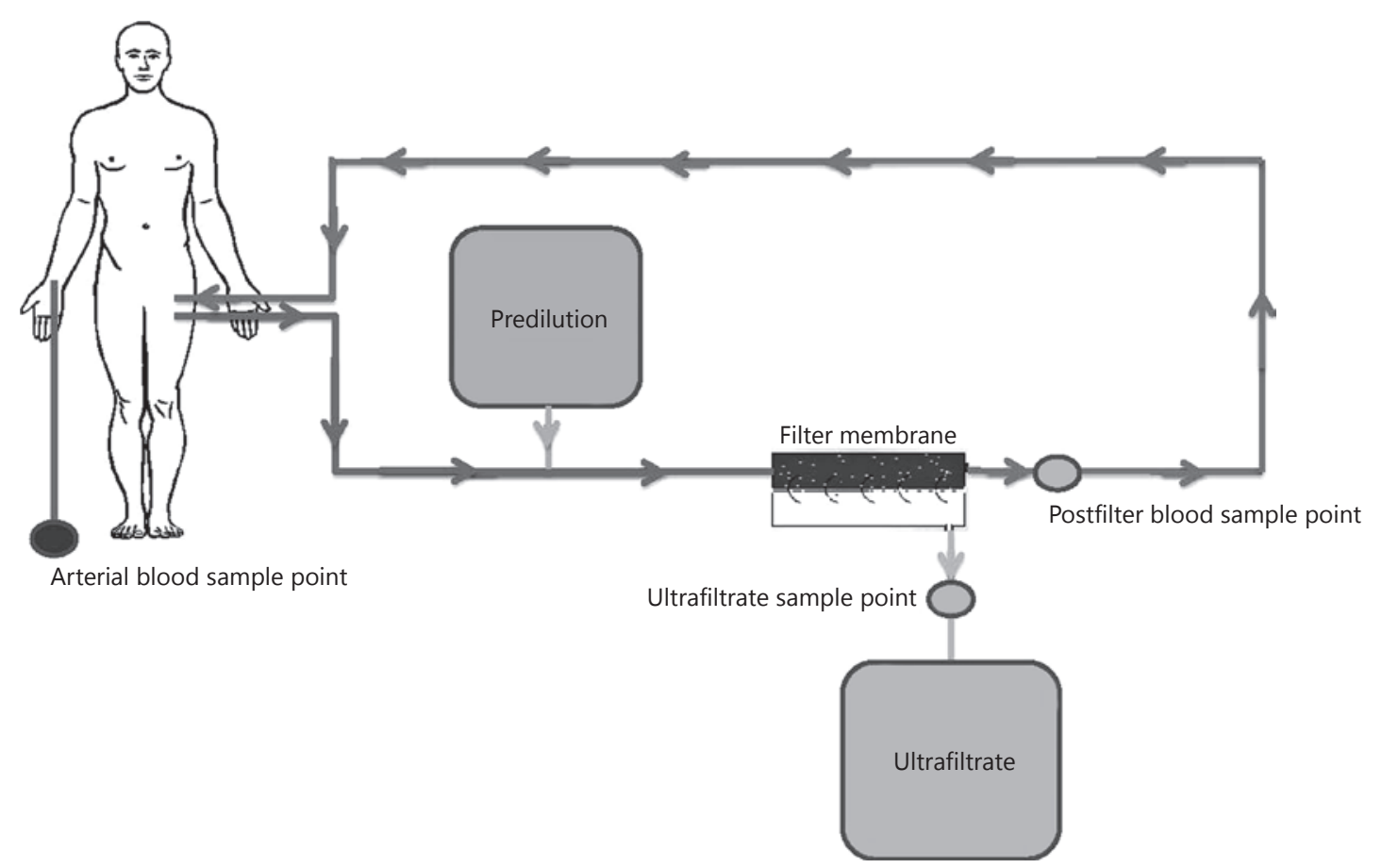

Fig. 1. Schematic drawing of the CVVH circuit with the different sample points shown. UF, ultrafiltrate.

\section{AA Loss in the Filter}

AA losses in the filter are presented in Figure 2. Patient 8 (acute liver failure) lost the greatest amount of AA (mean $2,213 \mathrm{mg} / \mathrm{h}$, equivalent to $53.1 \mathrm{~g} /$ day). Based on all samples, the estimated median AA loss in the filter was 435 $\mathrm{mg} / \mathrm{h}$ (351-635 mg/h), corresponding to a median AA loss of $10.4 \mathrm{~g} /$ day $(8.4-15.2 \mathrm{~g} /$ day). AA loss in the filter did not change significantly over the 24 -h study period (Table 3 ).

\section{AA Loss by Ultrafiltration}

AA loss by ultrafiltration is presented in Figure 2. Median AA loss by UF was $559 \mathrm{mg} / \mathrm{h}$ (491-725 mg/h), corresponding to a median daily UF loss of $13.4 \mathrm{~g} /$ day (11.8$17.4 \mathrm{~g} /$ day). UF loss did not change significantly over the 24 h study period (Table 3 ).

\section{Filter Loss Minus UF Loss}

The median difference between filter loss and UF loss was $-123 \mathrm{mg} / \mathrm{h}(-249$ to $-58 \mathrm{mg} / \mathrm{h})$, corresponding to $-2.9 \mathrm{~g} /$ day $(-5.9$ to $-1.4 \mathrm{~g} /$ day $)$. The absolute range of this difference was -443 to $+243 \mathrm{mg} / \mathrm{h}$, suggesting that some AA were "generated" in the filter and some were "lost". The filter minus UF loss did not change significantly over the study period (Table 3). Filter loss minus UF loss for the individual AA is shown in Figure 3.

\section{Sieving Coefficients}

The mean calculated SC of the individual AA are shown in Figure 4.

\section{Clearance of individual $A A$}

The individual AA clearances are shown in online supplementary Table 2 .

\section{Discussion/Conclusion}

Our study in critically ill patients demonstrates that the median total AA loss during the first $24 \mathrm{~h}$ of a CVVH session, using a high-flux polysulfone filter membrane, was $13.4 \mathrm{~g}$, while the median AA loss in the filter was $10.4 \mathrm{~g}$. AA loss in the filter therefore appeared to be lower than loss by ultrafiltration, indicating that adsorption does not play an important role when using a polysulfone membrane. However, individual AA behaved differently. The difference was positive for some and negative for others, suggesting that some AA were consumed or adsorbed, and others appeared to be locally generated and subsequently filtered. Our findings implicate that AA loss during CVVH is considerable and may contribute to a negative protein balance. Furthermore, measur- 
Table 1. Mass transfer and SC calculations

$$
\begin{aligned}
& \text { Mass transfer calculations } \\
& \mathrm{AA}_{\text {loss in the filter }}=\mathrm{AA}_{\text {circuit in }}-\mathrm{AA}_{\text {filter outlet }} \\
& \mathrm{AA}_{\text {circuit in }}=\left[\mathrm{AA}_{\mathrm{pl}}\right] * \mathrm{Q}_{\mathrm{pl} \text { prefilter }} \\
& \mathrm{Q}_{\mathrm{pl} \text { prefilter }}=(1-\mathrm{Ht} \text { prefilter } \\
& \mathrm{AA}_{\text {filter outlet }}=\left[\mathrm{AA}_{\mathrm{pl} \text { postfilter }}\right] * \mathrm{Q}_{\mathrm{pl} \text { postfilter }} \\
& \mathrm{Q}_{\mathrm{pl} \text { postfilter }}=\mathrm{Q}_{\mathrm{pl} \text { prefilter }}+\mathrm{Q}_{\text {predil }}-\mathrm{Q}_{\mathrm{uf}} \\
& \mathrm{AA}_{\text {loss by ultrafiltration }}=\left[\mathrm{AA}_{\mathrm{uf}}\right] * \mathrm{Q}_{\mathrm{uf}}
\end{aligned}
$$

$S C$ of the individual AA

$$
S C=\frac{2 *\left[A A_{u f}\right]}{\left[A A_{p l \text { prefilter }}\right]+\left[A A_{p l \text { postfilter }}\right]}
$$$$
\left[A A_{\text {plprefilter }}\right]=\left[A A_{p l}\right] * \frac{Q_{\text {plprefilter }}}{Q_{\text {plprefilter }}+Q_{\text {predil }}}
$$

Where $\left[\mathrm{AA}_{\mathrm{pl}}\right]$ : AA concentration in the plasma $(\mu \mathrm{mol} / \mathrm{L}), \mathrm{Q}_{\mathrm{pl}}$ prefilter: prefilter plasma flow rate, before the administration of the predilution replacement fluid $(\mathrm{L} / \mathrm{h}), \mathrm{Ht}_{\text {prefilter }}$ : $\mathrm{Ht}$ before administration of the predilution replacement fluid, $\mathrm{Q}_{\mathrm{bl}}$ : blood flow rate before the administration of predilution replacement fluid $(\mathrm{L} / \mathrm{h})$, $\left[\mathrm{AA}_{\mathrm{pl} \mathrm{postfilter}}\right]$ : AA concentration in the postfilter plasma $(\mu \mathrm{mol} / \mathrm{L})$, $\mathrm{Q}_{\mathrm{pl} \text { postfilter: }}$ the postfilter plasma flow rate $(\mathrm{L} / \mathrm{h}), \mathrm{Q}_{\text {predil }}$ : the predilution replacement fluid flow rate $(\mathrm{L} / \mathrm{h}), \mathrm{Q}_{\mathrm{uf}}$ : ultrafiltration flow rate $(\mathrm{L} / \mathrm{h}),\left[\mathrm{AA}_{\mathrm{uf}}\right]$ : AA concentration in the ultrafiltrate $(\mu \mathrm{mol} / \mathrm{L})$,

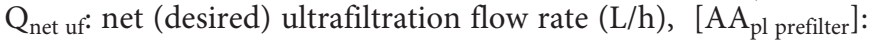
AA concentration in the plasma prefilter, after administration of the predilution replacement fluid.

SC, sieving coefficient; AA, amino acids; Ht, hematocrit.

ing AA loss in the filter, as we did, may underestimate total AA loss.

Our primary aim was to determine AA loss by UF and adsorption separately. Finding a lower loss when measuring the difference between blood circuit inlet and circuit outlet than by measuring loss directly from UF, and therefore, a "negative adsorption" was unexpected. Several in vitro studies have shown considerable adsorptive losses of proteins, peptides, and antibiotics under filtration conditions using different membranes [11-17]. We expected to find some degree of AA adsorption that would decrease over time due to saturation of the filter membrane. Druml [20] suggested that adsorption to synthetic membranes occurs primarily in the first hour after a new filter placement with filter saturation occurring after 4-8 h. De Vriese et al. [14] found that cytokine adsorption to an AN69 membrane steadily decreased after filter change and found indications for filter saturation after $12 \mathrm{~h}$. An explanation for the absence of overall adsorption could be that the molecular sizes of AA are so small (average 110 Daltons) compared to the pores of the high-flux membrane and that they are readily filtered and do not adhere to the membrane, at least not permanently.

Although our data suggest an overall lower loss in the filter than by UF, individual AA behaved remarkably different. Several processes have been identified that may influence the fluxes and balances over the membrane and thus the measured concentrations and SC. First, there may be direct interactions between charged AA with charged proteins that bind to the filter membrane. Second, the Gibbs-Donnan effect may cause unequal distribution of charged solutes across the membrane. The Gibbs-Donnan effect is caused by charged substances (such as circulating proteins) that are unable to pass the membrane and thus create an uneven electrical charge. Third, local generation and subsequent convection would lead to a calculated SC of $>1$. Uchino et al. [21] showed that during isovolemic hemodilution with predilution, both chloride and glucose had an SC of $>1$ and that the SC of $\mathrm{Na}$ and $\mathrm{K}$ was $<1$. They also found an SC of $>1$ for urea at increasing predilution, probably as a result of dilution and subsequent release of urea from erythrocytes. The SC of $>1$ for glucose remained unexplained [21]. Another explanation may be that the assumption that AA concentrations in arterial blood are the same as in the filter inlet is incorrect. Indeed, skeletal muscle and the brain are known producers of glutamine and alanine, thereby increasing the concentration in the femoral and jugular vein, respectively, compared to arterial blood. Others found an arteriovenous glutamine concentration difference in critically ill patients during CVVH [22]. Generation of glutamine could have led to higher circuit inlet concentrations than the arterial concentration that we used. Whether other AA can be produced in substantial amounts too is less well established. During hemodialysis, the reduction of the plasma AA pool accounted for $<20 \%$ of the total dialysate loss. Enhanced appearance of new AA during dialysis, most likely from tissue stores such as skeletal muscle, was suggested [23].

Also, recirculation can alter local concentrations of AA depending on the SC, by mixing inlet and outlet concentrations. Moreover, AA may bind to each other and form complexes that act differently than individual AA [24]. Furthermore, erythrocytes, leucocytes, and 
Table 2. Baseline and clinical characteristics of the study population

\begin{tabular}{|c|c|c|c|c|c|c|c|c|c|c|}
\hline 1 & Female & 56 & 1.65 & 70 & Sepsis & 39 & Sepsis & EN & 30 & Yes \\
\hline 2 & Male & 68 & 1.75 & 90 & Cholesterol emboli & 22 & Ischemia & None & 0 & Yes \\
\hline 3 & Male & 79 & 1.82 & 90 & Aortic enteral fistula & 19 & Ischemia & EN & 28 & No \\
\hline 5 & Male & 74 & 1.85 & 90 & $\begin{array}{l}\text { Mycotic aneurysm } \\
\text { after EVAR }\end{array}$ & 29 & Major surgery & $\mathrm{EN}$ & 97 & Yes \\
\hline 6 & Female & 22 & 1.65 & 55 & Trauma & 31 & Ischemia & EN & 20 & Yes \\
\hline 7 & Male & 58 & 1.84 & 78 & $\begin{array}{l}\text { Post cardiac arrest } \\
\text { with bowel ischemia }\end{array}$ & 28 & Sepsis & $\mathrm{PN}$ & 90 & Yes \\
\hline 9 & Female & 75 & 1.64 & 65 & Sepsis & 28 & Sepsis & EN & 85 & Yes \\
\hline 10 & Male & 75 & 1.65 & 65 & Post cardiac arrest & 40 & Ischemia & EN & 81 & Yes \\
\hline
\end{tabular}

AKI, acute kidney injury; APACHE, Acute Physiology and Chronic Health Evaluation; EVAR, endovascular aneurysm repair; EN, enteral nutrition; $\mathrm{PN}$, parenteral nutrition.

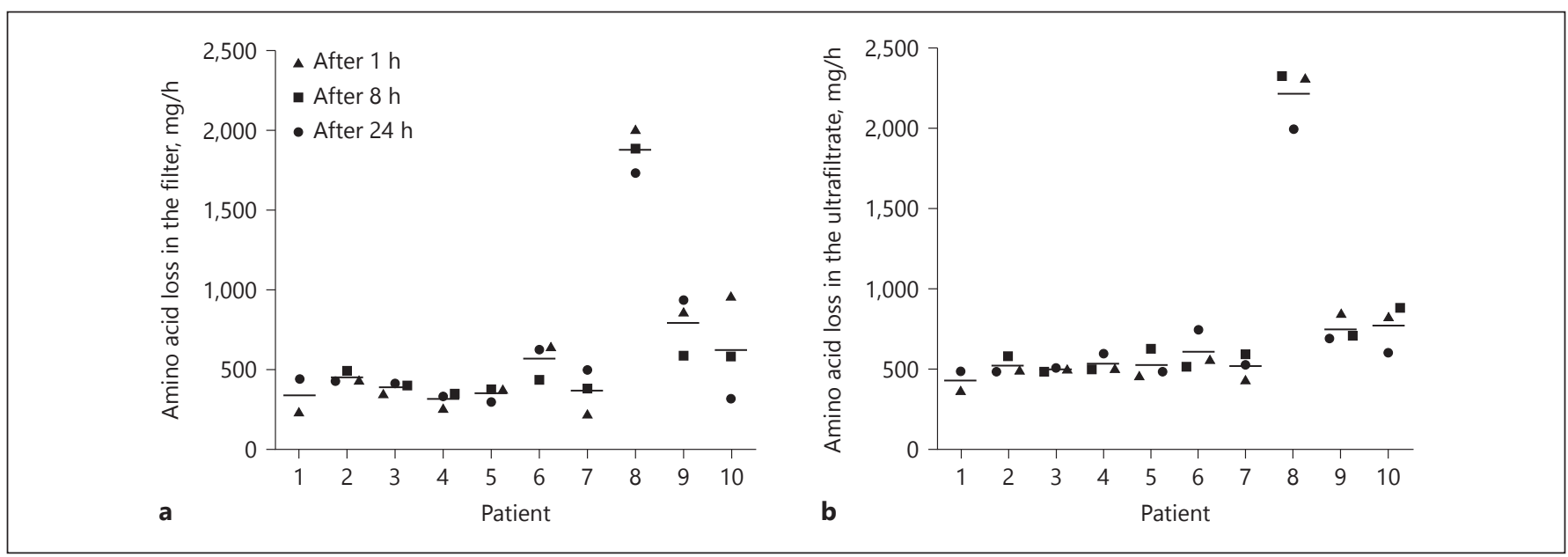

Fig. 2. AA loss in the filter (a) and in the UF (b) per patient over the 24-h study period. Lines represent the mean AA loss (mg/h) for that patient during the 24-h study period. UF, ultrafiltrate; AA, amino acids.

platelets all contain free AA. These may be released when their membrane permeability changes or during hydrostatic disequilibrium due to predilution and subsequent ultrafiltration. For example, taurine has a crucial role in cell volume homeostasis and can restore the osmotic imbalance in case of hyper- or hypotonicity [25]. Taurine also has anti-oxidant and anti-inflammatory properties and may be locally consumed. Finally, activated leucocytes and platelets may take up AA for metabolic support. 
Fig. 3. Filter loss minus UF loss in $\mathrm{mg} / \mathrm{h}$ for the individual AA. Glu, glutamate; Asn, asparagine; Ser, serine; Gln, glutamine; His, histidine; Gly, glycine; Thr, threonine; Cit, citruline; Arg, arginine Ala, alanine; Tau, taurine; Aab, a-aminobutyric acid; Tyr, tyrosine; Val, valine; Met, methionine; Ile, isoleucine; Phe, phenylalanine; Trp, tryptophane; Leu, leucine; Orn, ornithine; Lys, lysine. UF, ultrafiltrate.

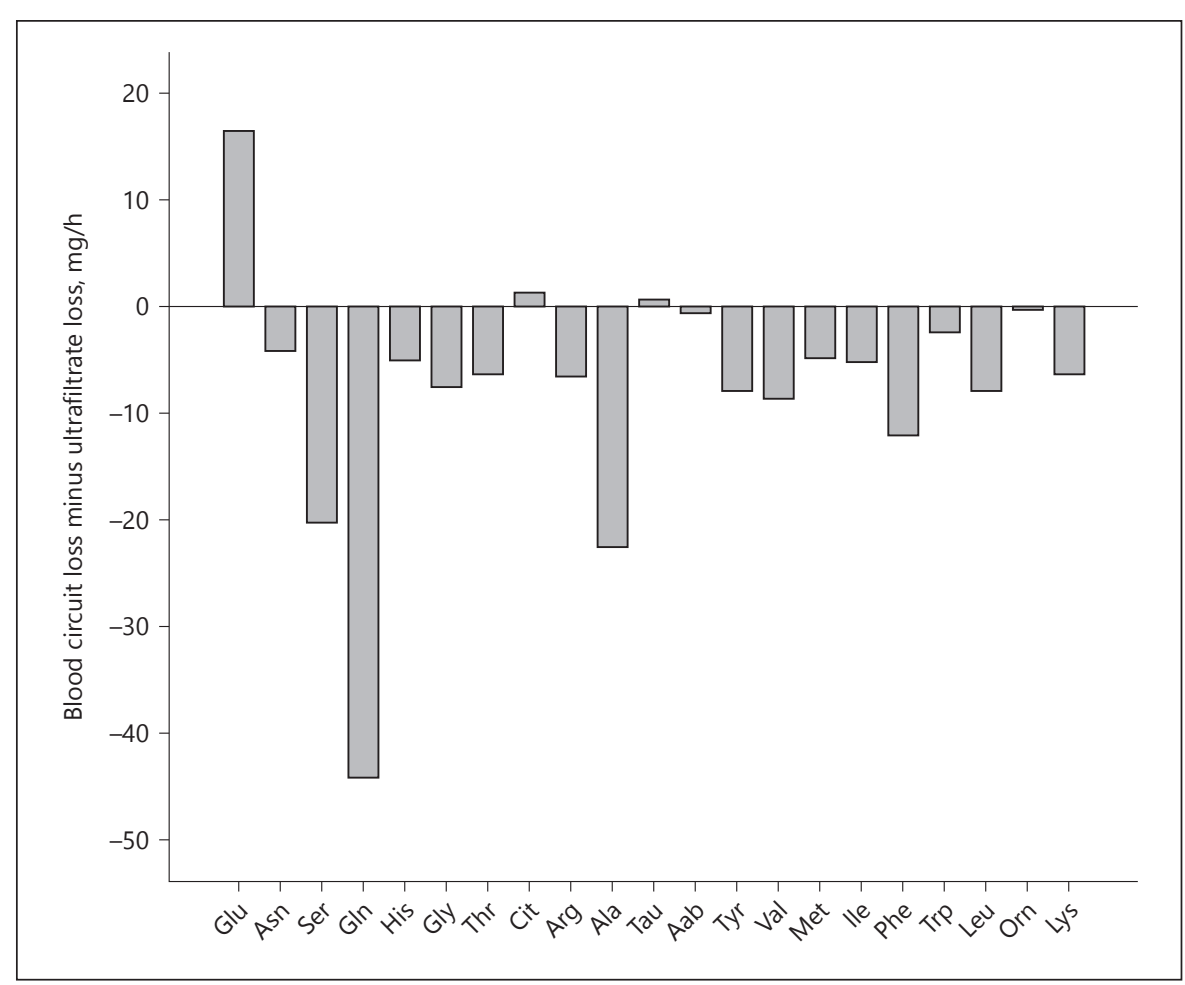

Table 3. AA loss in the filter, in the UF, and their difference at 1,8 , and $24 \mathrm{~h}$ after the start of CVVH session

\begin{tabular}{|c|c|c|c|c|}
\hline & $\mathrm{T} 1, \mathrm{mg} / \mathrm{h}^{\mathrm{a}}$ & $\mathrm{T} 8, \mathrm{mg} / \mathrm{h}^{\mathrm{a}}$ & $\mathrm{T} 24, \mathrm{mg} / \mathrm{h}^{\mathrm{a}}$ & $p$ value $^{\mathrm{b}}$ \\
\hline Filter AA loss & 435 (306 to 916$)$ & $420(369$ to 585$)$ & $435(329-702)$ & 0.72 \\
\hline UF AA loss & 508 (479 to 839$)$ & 587 (493 to 751) & $563(486-704)$ & 0.84 \\
\hline Filter loss minus UF loss & $-76.6(-229$ to 52$)$ & $-139(-262$ to -88$)$ & $-105(-263$ to -42$)$ & 0.41 \\
\hline
\end{tabular}

${ }^{\text {a }}$ Results in median (25-75th percentile).

${ }^{b}$ Change over time (ANOVA).

AA, amino acid; UF, ultrafiltrate; CVVH, continuous venovenous hemofiltration; ANOVA, analysis of variance.

\section{Sieving Coefficient}

Due to the small molecular size of AA, an SC of 1 is expected. However, 14 out of 20 AA had an SC above 1 with alanine having the highest SC (1.07), suggesting "facilitated transport" or local production at the blood side and subsequent convection. The SC of glutamate (0.60), taurine (0.83), tryptophan (0.84), and ornithine (0.85) were below 1 . The low SC of glutamate has been reported previously $[2,10]$. Glutamate is negatively charged in physiologic conditions and may therefore be repelled by the negatively charged polysulfone filter membrane. It is known that during deproteinization of samples, the tryptophane concentration decreases because it binds with plasma proteins. The abovementioned partially unknown and unexplained processes at the membrane influence the calculated SC, which does not necessarily reflect restricted or "facilitated" membrane passage. Most importantly, organ production of AA inducing a higher concentration in the venous compared to the arterial compartment will induce an overestimation of the SC.

\section{AA Clearance}

Individual AA clearances ranged from $16.6 \mathrm{~mL} / \mathrm{min}$ for glutamate to $36.4 \mathrm{~mL} / \mathrm{min}$ for alanine. Previous studies reported not only similar but also higher or lower AA clearances $[1,3,6,7,10]$. These discrepancies are likely caused by differences in CRRT dose and modality, and type of filter. 
Fig. 4. SC of the individual AA. The SC is the ratio of the solute filtrate concentration to the respective solute plasma concentration. An SC of 1 indicates unrestricted transport; an SC of 0 means no transport at all. The mean SC of the 3 different time points are given. Glu, glutamate; Asn, asparagine; Ser, serine; Gln, glutamine; His, histidine; Gly, glycine; Thr, threonine; Cit, citruline; Arg, arginine Ala; alanine; Tau, taurine; Aab, $\alpha$ - aminobutyric acid; Tyr, tyrosine; Val, valine; Met, methionine; Ile, isoleucine; Phe, phenylalanine; Trp, tryptophane; Leu, leucine; Orn, ornithine; Lys, lysine; SC, sieving coefficient.

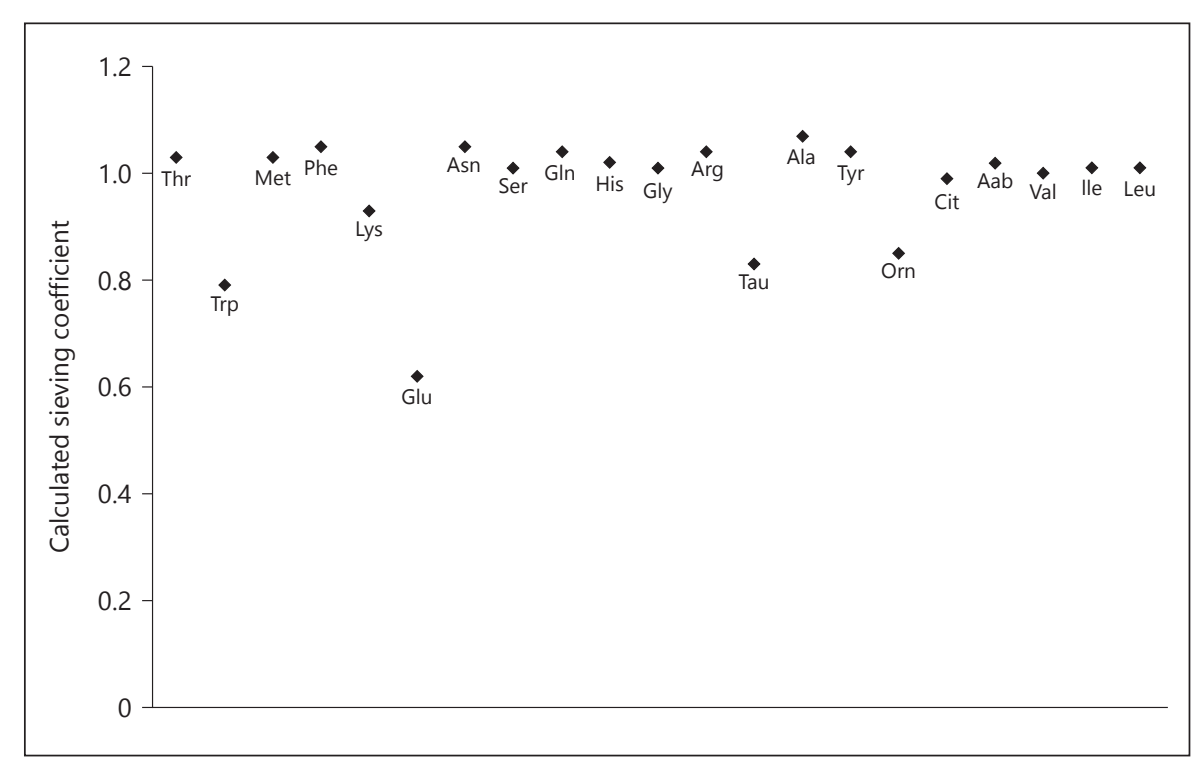

\section{Strengths and Limitations}

To our knowledge, this is the first study reporting adsorptive AA loss during CVVH in vivo. AA concentrations were measured using state-of-the-art techniques.

Our study has some limitations. Sample size of our study was small, yet in accordance with other studies. With the exception of patient 8 having acute liver failure, differences in AA loss between patients were small and consistent. We did not measure AA profile in the first hour of hemofiltration, thus very early adsorption could have been missed. AA levels in the arterial blood sample at baseline were used to calculate prefilter AA concentration at $1 \mathrm{~h}$ to reduce costs. A difference in arterial AA concentration between baseline and at $1 \mathrm{~h}$ would lead to over- or underestimation of actual AA loss, which could play a role in case of massive fluid infusion or removal. Because fluid infusion was massive during the first sample time point in patient 1 , we removed this sample from the analysis. Furthermore, another limitation of our study is that we used an arterial sample for prefilter concentration (see above). However, this does not impact the total amount of AA loss during CVVH. Furthermore, the mass transfer calculations assume a constant blood and predilution flow. In practice, CVVH (blood) flow is not constant [26]. If, as a result the ratio of predilution flow to blood flow changes, actual plasma concentrations at the blood site of the membrane may differ from calculated concentrations. However, the consistency of our findings over time supports the reliability of our results and is in accordance with other studies $[1,10]$. Our study does not show whether adsorption, local consumption or genera- tion, skeletal muscle or brain AA production, or other unknown mechanisms explain the differences between the loss in the blood circuit and by UF. Further studies are needed to elucidate these intriguing events. Finally, our results are only applicable to the specific polysulfone hemofilter and CVVH effluent rate we used. Nowadays, polysulfone is the most commonly used membrane and the CRRT dose is applied according to current guidelines.

\section{Clinical Implications}

The estimated median total AA loss of $13.4 \mathrm{~g} /$ day corresponds to a total loss of 11.2 grams of protein per day. The median protein intake in our study population was $56 \mathrm{~g} /$ day; therefore, $20 \%$ of nutritional protein intake was lost during $\mathrm{CVVH}$, potentially inducing or aggravating protein malnutrition. Increasing protein intake in patients on CVVH seems therefore rational. Scheinkestel et al. [8] found that a protein intake as high as $2.5 \mathrm{~g} / \mathrm{kg} / \mathrm{day}$ neutralized nitrogen balance and corrected AA deficiencies in patients receiving CVVH. Also, Bellomo et al. [3] found near-neutral nitrogen balance at parenteral nutrition administration containing $2.5 \mathrm{~g} \mathrm{AA} / \mathrm{kg} /$ day. However, a neutral nitrogen balance does not necessarily imply better patient outcome. Nowadays, a protein intake of $1.3 \mathrm{~g} / \mathrm{kg} /$ day is recommended for the general ICU population [27]. Nonetheless, unless liver failure or other disturbances in protein handling are present, it seems rational to increase daily protein intake by $10-15 \mathrm{~g}$ in patients on continuous RRT to compensate for the loss of AA. Whether a higher protein intake is safe and leads to improved outcome remains to be shown. 


\section{Conclusion}

During CVVH with a modern polysulfone membrane, the estimated AA loss was $13.4 \mathrm{~g} /$ day, corresponding to a loss of about $11.2 \mathrm{~g}$ of protein per day. Adsorption does not play a major role. However, individual AA behaved differently, suggesting complex interactions and processes at the filter membrane or peripheral production.

\section{Acknowledgements}

Not applicable.

\section{Statement of Ethics}

The Medical Ethics Committee of the VU University Medical Center waived the need for informed consent because no extra burden or risk was associated and patient data were coded (METC number 2013/308).

\section{Disclosure Statement}

S.N.S. has received research support from Nestle and congress support from Baxter. H.M.O. has received research support from Fresenius and speaking honoraria from Fresenius, Nutricia, and Nestlé. The other authors have no conflicts of interest to declare.

\section{Funding Sources}

Not applicable.

\section{Author Contributions}

H.M.O., S.N.S., and A.R.J.G. designed the study. S.N.S. and R.J.B. obtained the data and were responsible for the data management. S.N.S., P.J.T., and M.G.V. analyzed the data. H.M.O. had primary responsibility for the collection, analysis, and interpretation of the data and the final content. All authors contributed to drafting and writing the manuscript. All authors read and approved the final manuscript.

\section{References}

1 Davies SP, Reaveley DA, Brown EA, Kox WJ. Amino acid clearances and daily losses in patients with acute renal failure treated by continuous arteriovenous hemodialysis. Crit Care Med. 1991 Dec;19(12):1510-5.

2 Davenport A, Roberts NB. Amino acid losses during continuous high-flux hemofiltration in the critically ill patient. Crit Care Med. 1989 Oct;17(10):1010-4.

3 Bellomo R, Tan HK, Bhonagiri S, Gopal I, Seacombe J, Daskalakis M, et al. High protein intake during continuous hemodiafiltration: impact on amino acids and nitrogen balance. Int J Artif Organs. 2002 Apr;25(4):261-8.

4 Mokrzycki MH, Kaplan AA. Protein losses in continuous renal replacement therapies. J Am Soc Nephrol. 1996 Oct;7(10):2259-63.

5 Umber A, Wolley MJ, Golper TA, Shaver MJ, Marshall MR. Amino acid losses during sustained low efficiency dialysis in critically ill patients with acute kidney injury. Clin Nephrol. 2014 Feb;81(2):93-9.

6 Frankenfield DC, Badellino MM, Reynolds HN, Wiles CE 3rd, Siegel JH, Goodarzi S. Amino acid loss and plasma concentration during continuous hemodiafiltration. JPEN J Parenter Enteral Nutr. 1993 Nov-Dec;17(6) 551-61.

7 Chua HR, Baldwin I, Fealy N, Naka T, Bellomo R. Amino acid balance with extended daily diafiltration in acute kidney injury. Blood Purif. 2012;33(4):292-9.

8 Scheinkestel CD, Adams F, Mahony L, Bailey M, Davies AR, Nyulasi I, et al. Impact of increasing parenteral protein loads on amino acid levels and balance in critically ill an- uric patients on continuous renal replacement therapy. Nutrition. 2003 Sep;19(9): 733-40.

9 Navarro JF, Marcén R, Teruel JL, Martin del Río R, Gámez C, Mora C, et al. Effect of different membranes on amino-acid losses during haemodialysis. Nephrol Dial Transplant. 1998 Jan;13(1):113-7.

10 Maxvold NJ, Smoyer WE, Custer JR, Bunchman TE. Amino acid loss and nitrogen balance in critically ill children with acute renal failure: a prospective comparison between classic hemofiltration and hemofiltration with dialysis. Crit Care Med. 2000 Apr;28(4): $1161-5$.

11 Clark WR, Macias WL, Molitoris BA, Wang $\mathrm{NH}$. Plasma protein adsorption to highly permeable hemodialysis membranes. Kidney Int. 1995 Aug;48(2):481-8.

12 Birk HW, Kistner A, Wizemann V, Schütterle G. Protein adsorption by artificial membrane materials under filtration conditions. Artif Organs. 1995 May; 19(5):411-5.

13 Bouman CS, van Olden RW, Stoutenbeek CP. Cytokine filtration and adsorption during pre- and postdilution hemofiltration in four different membranes. Blood Purif. 1998; 16(5):261-8.

14 De Vriese AS, Colardyn FA, Philippé JJ, Vanholder RC, De Sutter JH, Lameire NH. Cytokine removal during continuous hemofiltration in septic patients. J Am Soc Nephrol. 1999 Apr;10(4):846-53.

15 K N Lam P, Tian Q, Ip M, Gomersall CD. In vitro adsorption of gentamicin and netilmicin by polyacrylonitrile and polyamide hemofil- tration filters. Antimicrob Agents Chemother. 2010 Feb;54(2):963-5.

16 Choi G, Gomersall CD, Lipman J, Wong A, Joynt GM, Leung P, et al. The effect of adsorption, filter material and point of dilution on antibiotic elimination by haemofiltration an in vitro study of levofloxacin. Int J Antimicrob Agents. 2004 Nov;24(5):468-72.

17 Lewis SJ, Switaj LA, Mueller BA. Tedizolid Adsorption and Transmembrane Clearance during in vitro Continuous Renal Replacement Therapy. Blood Purif. 2015;40(1):6671.

18 Schilder L, Nurmohamed SA, Bosch FH, Purmer IM, den Boer SS, Kleppe CG, et al.; CASH study group. Citrate anticoagulation versus systemic heparinisation in continuous venovenous hemofiltration in critically ill patients with acute kidney injury: a multi-center randomized clinical trial. Crit Care. 2014 Aug; 18(4):472.

19 Uhe AM, Collier GR, McLennan EA, Tucker DJ, O'Dea K. Quantitation of tryptophan and other plasma amino acids by automated precolumn o-phthaldialdehyde derivatization high-performance liquid chromatography: improved sample preparation. J Chromatogr A. 1991 Mar;564(1):81-91.

20 Druml W. Metabolic aspects of continuous renal replacement therapies. Kidney Int Suppl. 1999 Nov;56(72):S56-61.

21 Uchino S, Cole L, Morimatsu H, Goldsmith D, Ronco C, Bellomo R. Solute mass balance during isovolaemic high volume haemofiltration. Intensive Care Med. 2003 Sep;29(9): 1541-6. 
22 Berg A, Norberg A, Martling CR, Gamrin L, Rooyackers O, Wernerman J. Glutamine kinetics during intravenous glutamine supplementation in ICU patients on continuous renal replacement therapy. Intensive Care Med. 2007 Apr;33(4):660-6.

23 Ikizler TA, Flakoll PJ, Parker RA, Hakim RM. Amino acid and albumin losses during hemodialysis. Kidney Int. 1994 Sep;46(3):830-7.
24 Biro JC. Amino acid size, charge, hydropathy indices and matrices for protein structure analysis. Theor Biol Med Model. 2006 Mar; $3(1): 15$.

25 Vermeulen MA, van Stijn MF, Visser M, Lemmens SM, Houdijk AP, van Leeuwen PA, et al. Taurine Concentrations Decrease in Critically Ill Patients With Shock Given Enteral Nutrition. JPEN J Parenter Enteral Nutr. 2016 Feb;40(2):264-72.
26 Baldwin I, Bellomo R, Koch B. Blood flow reductions during continuous renal replacement therapy and circuit life. Intensive Care Med. 2004 Nov;30(11):2074-9.

27 Singer P, Blaser AR, Berger MM, Alhazzani W, Calder PC, Casaer MP, et al. ESPEN guideline on clinical nutrition in the intensive care unit. Clin Nutr. 2019 Feb;38(1):4879. 